\title{
Moral Realism, Objective Values And J.L. Mackie
}

\section{JOHN M. MIZZONI}

\author{
Temple University
}

"There are no objective values" (p. 15).1 With this bold pronouncement John Mackie begins chapter one of Ethics: Inventing Right and Wrong and abruptly introduces the central thesis of his anti-realist metaethics. He grants that ordinary moral judgments presuppose objective values, but he holds that these values are mythical and much of his argument is meant to show why such belief in objective values is false. He aims to demonstrate how both ordinary moral thinking and philosophical moral theorizing can be successful without subscribing to objective values. This paper will address what real effect, if any, that Mackie's view has on moral realism. I will borrow Geoffrey Sayre-McCord's definition of realism as the view that makes two postulates: "(1) the claims in question, when literally construed, are literally true or false (cognitivism), and (2) some are literally true" (SayreMcCord 1988a: 5). Of course, the claims in question in this case are moral claims. This version of moral realism is intentionally modest and sketchy but I intend, as a consequence of my analysis of Mackie, to strengthen and make explicitly clear, my own version of moral realism.

My analysis of Mackie will cover the following areas: 1) his notion of objective value, 2) his metaethical methodology which I term the 'isolatory method', 3) his attempt at outlining a normative ethics in light of his metaethical skepticism, and 4) his understanding of the concept 'institution'. I shall offer a moral realist response to each of these areas and the rebuttals will culminate into a uniform thesis which I term 'contextual moral realism'.

The first necessary step in an analysis of Mackie's argument is to look more closely at what he means by saying, 'there are no objective values.' Mackie's sense of 'objective value' has an internalist overtone which is to say that objective values are (like) things which necessitate motivation to act. He says, "Plato's Forms give a dramatic picture of what objective values would have to be" and "..it is held.....that just knowing [the Forms] or 'seeing' them will not merely tell men what to do but will ensure that they do it" and "being acquainted with the Forms of the Good and Justice and Beauty and the rest, [the philosopher-kings] will, by this knowledge alone, without any further motivation, be impelled to pursue and promote these ideals" (pp. 23$24,40,49)$. But why do objective values "have to be", as Mackie says, necessarily motivating? To say that objective values must be this way, is an overstatement because there are other ways to conceive of objective values. For example, we can conceive them as non-necessarily motivating. It is quite easy to think of common everyday examples in which people admit that they know what the morally right thing to do is but other (non-moral) factors override their moral sense. Acting in accord with objective values is difficult and to cast them as necessarily motivating seems to me to be only one way (not the only way) of considering the nature of objective values. Even when we consider the philosopher-kings themselves who have received the best training and education it is conceivable that when absolute power of the state is conferred upon them, they might not be able to handle this new-found power. They are finite beings that are mutable and corruptible, not gods, and notwithstanding their knowledge of the Forms,

1 Unless otherwise stated, page references are to Ethics: Inventing Right and Wrong (London: Penguin Books, 1977). 
their ability to act in accordance with the Forms may get affected by their new practical role in human affairs.

Besides Plato, Mackie's view on what objective values would "have to be" may also be traceable to John Stuart Mill's objective utilitarianism. Mill's point that "education... should.....establish in the mind of every individual an indissoluble association between his own happiness and the good of the whole..." seems to be along the same lines as Plato's knowledge of the moral Forms which is supposedly attained through extensive education (Mill 1861: 17). It would be fair to say that both Plato and Mill were internalists because both agree that after becoming acquainted with moral knowledge (through education), the individual will be, ipso facto, motivated to bring about the greater good.

It is important to bear in mind that Mackie's attack on moral realism relies heavily on this old-fashioned account of internalist objective values. In defining objective values he uses an outdated, far-fetched internallymotivating concept and then offers arguments to show that this sort of value could not possibly exist because it is metaphysically and epistemologically queer. Of the 5 reasons Mackie offers against objective values, (1) relativity, (2) queerness, (3) supervenience, (4) knowledge of the supervenience relation, and (5) patterns of objectification in our language, (p.49), I will only focus on (2),(3) and (4) because only they pose genuine difficulties for the moral realist.

There is a well-known counter to (1) which Mackie himself recognizes and briefly discusses. Namely that "objective values....are not specific moral rules or codes but very general basic principles which are recognized at least implicitly to some extent in all society" (p. 37). He states that this counter is only partly effective against the argument from relativity. His reply is that in ordinary moral thought people do not only judge right or wrong with the use of these general principles but they also judge by the immediate response of their 'moral sense'. Due to the variable response of the moral sense, people will inevitably respond differently and consequently, relativity is issued in. But since Mackie makes a partial concession, namely that in addition to the moral sense people also use general principles in their moral reasoning, the argument from relativity (at least Mackie's formulation of it) is not in "full force" (p.38). 2

Mackie doesn't assert reason (5) as an independent reason for denying objective values. His rationale is that the above 4 reasons should persuade us to reject the common-sense belief in objective values "provided that we can explain how this belief, if it is false, has become established..." (p.42). So reason (5) is compelling only if reasons (1) though (4) are accepted.

The first point of this paper is to show that objective values as defined by Mackie may be rejected but there are other conceptions of objective value that can nevertheless be maintained. A more intuitive sense of objective value that Mackie considers but quickly dismisses is "that there are some things which are valued by everyone" (p.23). This is the sense of 'objective' which is close to what is usually meant by 'universal'. Although intuitive and perhaps less demanding than Mackie's sense of objective value, it is rejected for the reason that it does not capture the proper meaning of 'objective value'. The proper meaning, according to Mackie, is the meaning which is presupposed in normal, day-to-day moral judgments. He mentions that 'being valued by everyone' or the simple fact of agreement among people, does not entail objectivity. The agreement of everyone on certain values may simply reflect an intersubjectivity. Mackie maintains that an

2 For more on this issue see for e.g. Brink 1989, pp. 197-209. 
วył :ssauxaanb s!ył jnoqe 8u!gu!xq jo КeM

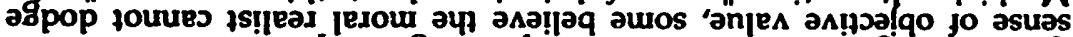

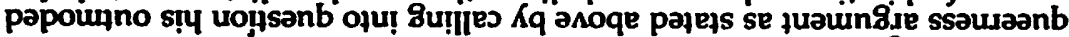

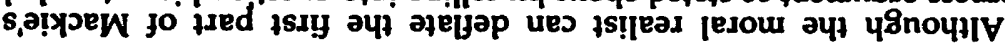

(8E

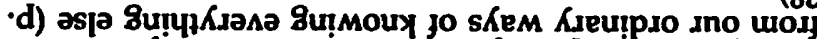

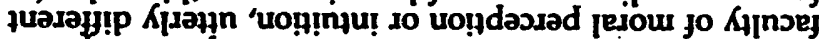

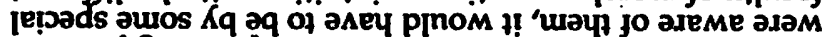

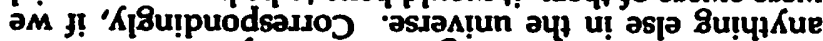

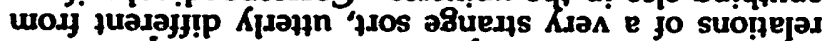

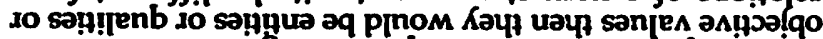

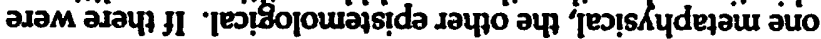

'squed omy sey ssauxaənb woy juaungre әчI

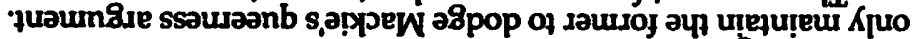

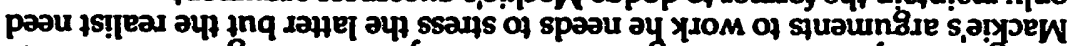

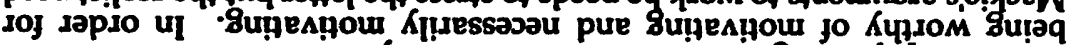

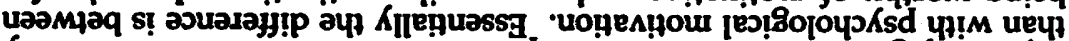



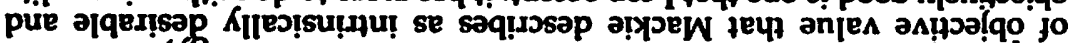

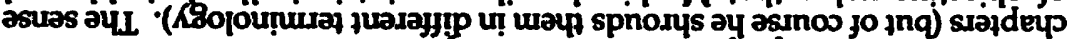

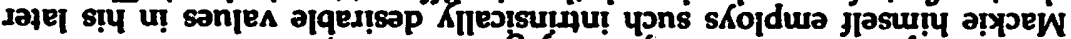

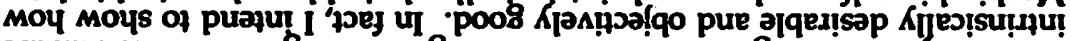

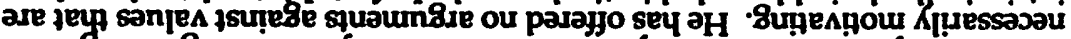
pue Su!p!nn8 uo!̣Je $\Lambda_{\mid[}$

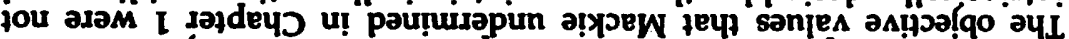

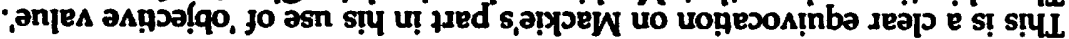

$\cdot(E x I \cdot d)$ I razdeq $\supset$ u! sanjen

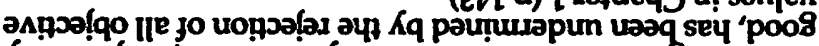

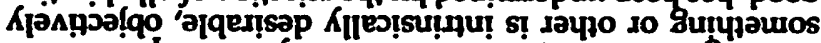

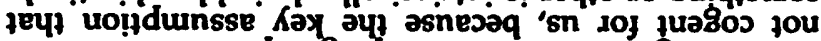

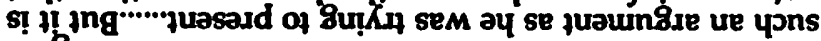

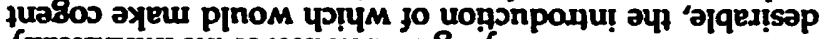

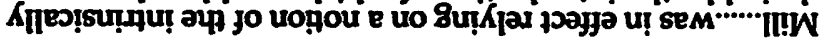

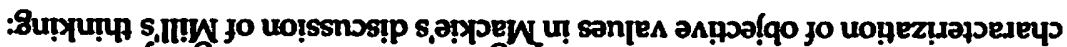

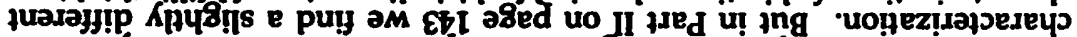

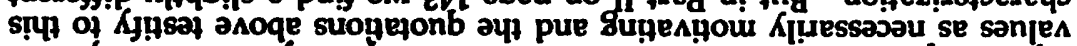

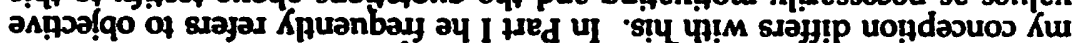

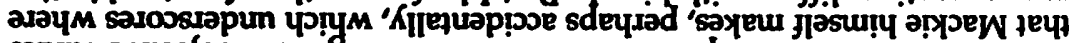

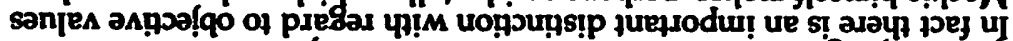

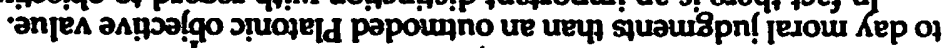

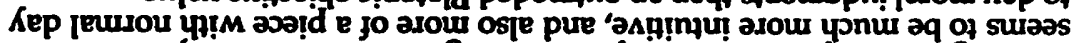

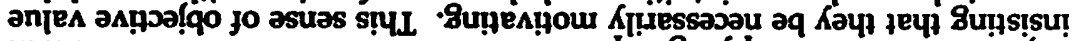

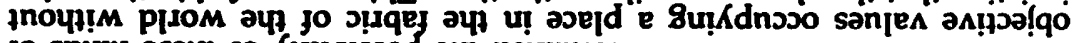



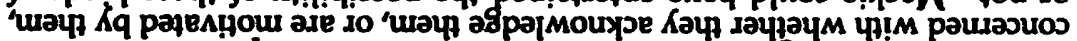

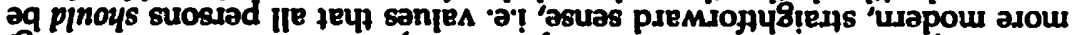

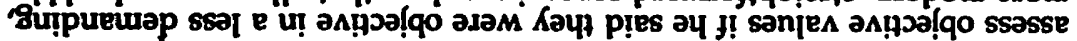

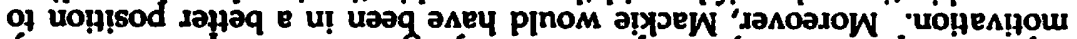

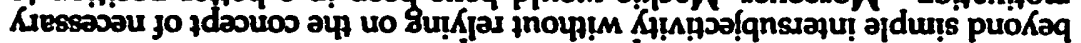

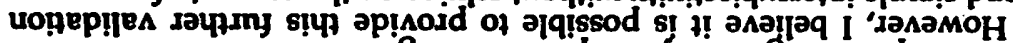

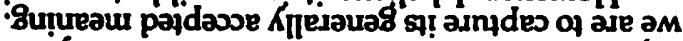

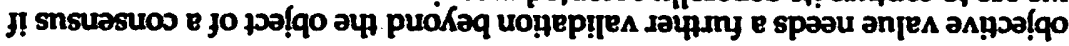


supervenience argument (p. 41).3 Mackie maintains that the moral realist has to explain how moral features are linked to natural features. But he believes it is a mystery how such a link can obtain, and further, if there was a link between these two domains of properties, then how can we discern the links?

Another way of bringing out this queerness is to ask, about anything that is supposed to have some objective moral quality, how this is linked with its natural features. What is the connection between the natural fact that an action is a piece of deliberate cruelty - say, causing pain just for fun-and the moral fact that it is wrong? It cannot be an entailment, a logical or semantic necessity. Yet it is not merely that the two features occur together. The wrongness must somehow be 'consequential' or 'supervenient'.... (p.41).

Although Mackie only briefly mentions this notion of 'supervenience', it is an issue that has occupied a prominent place in moral theorizing. This problem of accounting for the exact relationship between natural features and moral features has been made to look insuperable by recent opponents of moral realism, but my claim will be that the supervenience problem can be dealt with (and not, contra Horgan \& Timmons, just by labelling the relation sui generis). I intend to show that Mackie's supervenience difficulty stems from his radical empiricism, or as I term it - the isolatory method. It is a faulty metaethical procedure which has two essential components: 1) a certain conception of identity, and 2) empiricism. It might be useful in other areas of inquiry but for ethics it is an unnecessarily austere methodology.

According to those who advocate the supervenience argument against moral realism, the dichotomy between facts and values (or is's and ought's) is thought to be treacherous because we cannot establish a one-to-one identity correspondence between facts and values. I acknowledge that the moral realist must account for the relationship between moral features and natural features but I disagree that we need to uncover a one-to-one identity correspondence in order to understand the relationship properly.

For Mackie, the supervenience problem has a metaphysical aspect and an epistemological aspect. The metaphysical aspect is "how such values could be consequential or supervenient upon natural features," and the epistemological aspect is, "accounting for our knowledge of value entities or features and of their links with the features on which they would be consequential" (p.49). The identity correspondence criterion is part of the epistemological aspect and a re-statement of the difficulty, in somewhat clearer terms, is offered by Terence Horgan and Mark Timmons: "Even if goodness, for instance, is identical to some specific natural property, there remains the task of explaining why this natural property, rather than any other one(s), counts as the correct referent of the term goodness"' (Horgan \& Timmons 1992: 230). Both Mackie and his followers insist on isolating a oneto-one correspondence between a natural property and a moral property and when this cannot be done, they conclude that moral properties are not real. I don't believe we have to accept this identity criterion when looking for moral properties. In the later sections of the chapter I will offer an alternative method for locating the link between natural and moral features, viz., a contextual method.

3 e.g., Blackburn 1971, Blackburn 1988, Horgan \& Timmons, 1992. 
The second component of Mackie's isolatory method is his empiricism which is not to be confused with positivism. In the following passage he distinguishes between liberal empiricists and logical positivists:

\begin{abstract}
Although logical positivism with its verifiability theory of descriptive meaning gave an impetus to noncognitive accounts of ethics, it is not only logical positivists but also empiricists of a much more liberal sort who should find objective values hard to accommodate. Indeed, I would not only reject the verifiability principle but also deny the conclusion commonly drawn from it, that moral judgements lack descriptive meaning. The assertion that there are objective values or intrinsically prescriptive entities or features of some kind, which ordinary moral judgements presuppose, is, I hold, not meaningless but false (pp. 39-40).
\end{abstract}

Even though it is tempting to categorize Mackie as a non-cognitivist because he denies moral realism, it is more correct to consider him a cognitivist who held an error theory for he explicitly claims that he disagrees with the positivists in their opinion of ethical statements. Positivists maintain that moral statements are non-verifiable and therefore meaningless; whereas Mackie believes moral statements are meaningful and even take truthvalues. The truth-value that he feels belongs to objective value statements is false. There may be other kinds of value statements that he believes can be true. On page 25 he says "there are certain kinds of value statements which undoubtedly can be true or false, even if, in the sense I intend, there are no objective values" (p.25).

It is clear from the preceding quotation from the Ethics that Mackie believes only the positivists should be termed radical and he should not, but if we look closely at Mackie's arguments, I think Mackie's 'liberal' empiricism is also radical albeit in a different way. He thinks he is liberal because he grants that moral statements take truth values, but he is radical because he is asking too much, i.e., he employs an unnecessarily austere methodology of metaethical analysis. He is asking that an analysis of ethics provide him with clear fact/value correspondence and insight into the mysterious necessary motivation that is somehow to be found within objective values. Mackie's empiricist microscope, so to speak, will not detect objective values or moral facts. By becoming so enthralled in the metaethical meaning of moral terms, and analyzing each moral term discretely, he cannot see the interconnectedness of moral language and its relationship to the larger context of the human condition. He is trying to extract the meaning of moral concepts after stripping them out of the human context. He finds that in isolation, moral concepts like objective value for example, are "entities or qualities or relations of a very strange sort" (p. 38). This is an understandable conclusion because if we try to understand something by dissecting it into its primary elements, this alone will not lead us to understanding. As well as attending to the details of each individual moral term, we must also attempt to grasp the overall, general scheme in which the individual term resides. Radical empiricists suffer from a kind of myopia, or missing the big picture. This point comes out if we consider Hume's discussion of causation. In The Cement of the Universe, Mackie summarizes Hume's discovery:

his serious conclusion is the largely negative one that these [causal] inferences are to be ascribed to imagination and 
custom rather than to reason, that we do not discover any necessity in 'the objects' that could serve as a basis and justification for these inferences, but that instead our very idea of necessity arises from those inferences: the supposed necessity is based on the inference, not the inference upon any perceived necessity (Mackie 1974: 5-6).

Hume was trying to isolate causation and the only way he could do it was to ascribe it to imagination and custom. Because he didn't 'see' the transference, he couldn't 'see' the causation happening and this was enough for him to doubt that causal necessity was 'in the objects'. I take this as a paradigm example of radical empirical analysis which, when faced with isolation difficulties, chooses to interpret important elements such as causation, or objective values, in the mental imagination rather than in the fabric of the world.

In an early section of his Ethics Mackie remarks that he is interested in abandoning the linguistic analysis of moral terms because it generates more problems than it solves. He says, "the more work philosophers have done on meaning, both in ethics and elsewhere, the more complications have come to light" (p.20). This is why "it would be a mistake to concentrate second order ethical discussions on questions of meaning," and why Mackie chose to defend an ontological thesis (ibid). My point is that although Mackie overtly tried to escape the kind of moral theory that gets caught up in itself by analyzing and defining moral terms, he nevertheless retained an assumption that is embedded within this linguistic project. He is trying to understand ethics by breaking it down into primary elements. But when he looks at those elements, viz. the terms 'good, 'ought,' and 'objective value,' he doesn't see anything internally prescriptive about them. From this he concludes that a realist metaethics rests on queer elements that really don't exist because when he looked for them with his empiricist microscope he could not find them. So his underlying assumption is a radical empiricist one. He assumes that empiricism is a tool for locating all real things. Rather than say his tool failed he is prepared to say ethics is not real in the sense that the moral realist admits.

This concludes my analysis of the isolatory method and its two aspects of identity correspondence and radical empiricism. Now I intend to make good on a promissory note I extended earlier in my discussion of objective values. I intend to show how Mackie shrouds intrinsically desirable values in different terminology and proceeds to employ them in the later chapters of Ethics which are devoted to normative theory rather than metaethical analysis.

In the early parts of the book where he focuses solely on metaethical questions he seems to have an agenda in mind that is similar to the Cartesian method of doubt. Descartes intended to remove all thoughts from his mind and attempted to establish knowledge on solid foundations by piecing together thoughts that he could clearly and distinctly perceive to be true. It turns out that Descartes rebuilds knowledge to roughly the same state it was in before he tore it down. He ended up simply finding new arguments for the same old conclusions, for instance mind/body dualism and the existence of God. The same holds true for Mackie. In his metaethical discussions he wipes the slate clean by making ethics seem like something that we do not discover but that which we create. But later in his recommendations for what a normative theory should look like, he uses precisely those concepts which he previously wiped away. First he offers an attack on ethics and then for the rest of his book he is saying the same thing every other (conservative) ethicist before him said. 
Even Simon Blackburn, a fellow anti-realist, notices this: "in the second part of the book he is quite happy to go to express a large number of straightforward moral views about the good life, about whether it is permissible to commit suicide or abortion, and so on" (Blackburn 1993: 149. 150). Blackburn wonders why, if moral vocabulary is imbued with error, that we would choose to fall into error by developing a normative theory. He notes that Mackie feels legitimated in venturing into normative theory because he takes the Humean approach to morality, viz. that ethics is malleable not discoverable.

Mackie also feels he is justified in working up a normative theory because of his view that second-order moral views and first-order moral views are independent. Mackie holds that there is nothing wrong with being a skeptic about the former and a non-skeptic about the latter. "What I am discussing is a second order view....these first and second order views are not merely distinct but completely independent: one could be a second order moral sceptic without being a first order one, or again the other way round" (p.16). I think there is something wrong with this. I am not alone in believing there are logical and practical relations that obtain between metaethics and normative ethics (for e.g., Tannsjo 1976, Brink 1989). I think the connections between these types of moralizing will come out if we consider Mackie's covert use of 'objective values' in the later chapters of his book.

The general argument running through the whole of Mackie's Ethics reveals that he is striving for a pliable ethics which we can use to create whatever it is we dub as 'correct' ethical behavior. So although many of the earlier sections of the book are devoted to discussing the implausibility of objective values, the later sections give us a sketch of how we are to apply what we have discovered about ethics, viz. that it is wholly made by humans and not discovered in the fabric of the world. Mackie's intention is to develop a normative theory without the use of objective values, God or religion-a purely secular morality. In this paragraph I have been liberally using the first person plural, but it is a genuine question to ask Mackie just who this 'we' is that is inventing right and wrong. It is apparent from the following quotation that we' does not refer to humankind:

Mankind is not an agent; it has no unity of decision; it is therefore not confronted with any choices....a plurality of interacting rational agents does not in general constitute a rational agent, and......the resultant of a number of choices is not in general a choice (p. 122).

It is apparent from the following two quotations that we' somewhat refers to each human individually, but the individual must be a part of a social circle of varying size in order to be successful in altering the face of morality:

It does not follow....that an individual is free to invent a moral system at will. If a morality is to perform the sort of function described in Chapter 5, it must be adopted socially by a group of people in their dealings with one another. Of course, there can be and are larger and smaller social circles (p. 147).

What counts is rules that are actually recognized by the members of some social circle, large or small, and that thus set up expectations and claims. Innovations and reforms are not excluded, but they must be possibly 
actual, not purely utopian........ What the individual can do is to remember that there are, in the different circles of relationship with which he is concerned, various fragments of a moral system which already contributes very considerably to countering specifiable evils which he, like others, will see as evils: that he can.......put pressure on some fragments of the system, so that they come gradually to be more favourable to what he sees as valuable or worthwhile (p. 148).

Saying that we create morality rather than discover it sounds very antirealist but I will claim that a pliable ethics like the one just outlined in the two preceding quotations is quite compatible with a realist as well as an anti-realist theory. Take, for instance, the last line in the immediately preceding quote that indicates how the individual can attempt to modify the status quo moral system; this agent is trying to make the moral system more in line with what she takes as valuable or worthwhile. The realist can interject at this point that certain basic moral truths (those 'common moral principles' or 'intrinsically desirable values' mentioned earlier) will always be seen as valuable and worthwhile, that yes we learn about them through contingent circumstances but they nonetheless suggest moral knowledge.

Mackie's moral skepticism is a negative doctrine, it says what there isn't, namely objective values, and his subjectivism is a positive doctrine that says what there is, viz. subjective values. When Mackie is explaining his normative theory, then, he should only rely on subjective values. And pointing to the pliability of ethical systems seems to be consistent with a subjective value system. Because morals are essentially subjective, society should be liberal enough to allow for differing subjective tastes. Mackie seems to be making a Rawlsian point with the following:

....since there will always be divergent conceptions of the good, different preferred kinds of life, a good form of society must somehow be a liberal one, it must leave open ways in which different preferences can be realized...(p. 236).

This feature of a liberal society can be explained equally well by a realist theory or an anti-realist theory. The anti-realist will declare that society must permit a potpourri of subjective tastes because there are differing conceptions of the good. The claim that society should be sufficiently liberal to prevent the infringement of rights and privileges of its citizens can be explained by the realist by saying that this feature is an objective moral truth about societies.

The thing that I am trying to uncover, which I believe will help to understand and locate the precise point of departure between going from a natural fact to a moral fact, is Mackie's choice of direction to which he wishes to push ethics. If ethics is as pliant as he seems to argue, then the question comes up as to where or what we would like a 'good' ethics to lead. But first we must stipulate what it is that makes an ethics good. Is it good in an objectivist sense or in a subjective sense? Must we close our eyes to the metaethical questions, as Mackie does, when talking about normative issues? He does put forward goals that a first-order normative ethics should try to achieve and he offers some characteristics of what he believes would constitute a 'good ethics'. But what are the standards that enable him to say which goals we should seek and what are the ideas that underlie what it means to be a morality? He states that the function of morality "is primarily 
to counteract..... limitation of men's sympathies" (p.108). A realist way to look at it is to say that the function of morality is to implement objective values to the best of our ability. Since Mackie is offering a normative ethics which he thinks applies to everyone, the values he is pushing for sound objective in the sense that they ought to be universally endorsed even if we are not particularly motivated to do so. This is the alternative way of understanding objective value that I adumbrated above. I believe Mackie must implicitly rely on this kind of objective value if he is to get a normative ethics even off the ground. If every value is simply created and totally subjective then I have to ask why I should care to bother about sympathies or selfishness if I don't wish to? He is presupposing certain values here, viz. (1) sympathy is a good, and (2) unrestrained selfishness is an evil, but does it make sense to say that (1) and (2) are subjective values? In order for his normative theory to be internally consistent, it is required that these values he is relying upon are construed as objective. If Mackie is prepared to say that he is only offering his personal ethics which he does not intend to have any bearing on anyone else's ethics then it would be consistent to employ subjective values. But if he doesn't intend his discussion to reveal only his personal ethics (and it seems that he doesn't), then we can ask, why ought we believe that all moralities should have these elements? When he makes broad statements like 'the object of morality is such and such' or 'all morality is such and such', it seems as if he is making an objective statement. It is a statement that will apply to all moralities inclusively and exhaustively. On page 172 he says that "any plausible view of the good for man, any viable concept of happiness, will, I believe, have this general form." The form involves rights and property. To say that there is a good for man or that all men have certain rights sounds objective. Mackie cannot wiggle his way out of this by saying he has a very specific sense of what he means by objective value' because as I have shown above, his strict sense of objective value is factitious. These values that underlie Mackie's normative theory are objective in the straightforward sense that I have explained earlier, viz., 'values that should be valued by all persons whether they acknowledge them, or are motivated by them or not.' Since Mackie is presupposing these universal values in his normative theory, ones that are objective in the intrinsically desirable sense, I have shown that Mackie falls back on realist assumptions. Or at least that Mackie's pliable ethics is easily accommodated into a realist's perspective on ethics.

The remainder of the paper will be devoted to developing a kind of realism that is compatible with Mackie's notion of 'institution' which is an idea that he seems to borrow from John Searle. After Mackie has shown us that we cannot isolate the 'objective prescriptivity' in a natural fact, he teaches us that putative moral properties, those generally thought to exist objectively, in fact really exist only in a contextual setting of what he calls an 'institution.' He mentions, for example, that the is-ought gap can be bridged, albeit "only by speaking within some institution" (p.72). In his discussion of institutions, Mackie uses the example (which he takes from John Searle) of breaking a promise as an instance of immorality; it is only immoral against a suitable backdrop or an 'institution'. He agrees with this 'institutional' explanation but he feels that moral realism will only be vindicated if objective values are found to exist, in isolation, outside of an institution. It is important for Mackie's argument that he locate purported moral properties somewhere because they are referred to daily in normal discourse. Mackie says his theory is an 'error theory' because "although most people in making moral judgments implicitly claim, among other things, to be pointing to something objectively prescriptive, these claims are all false" (p.35). Thus Mackie offers a place, a setting in which these moral properties which we 
freely refer to, reside. Talk of moral properties only makes sense against a backdrop of an institution, but precisely because moral properties only reside in a context and not in isolation Mackie believes this confirms his thesis of the pliability of ethics or the true 'created' nature of ethics. He maintains that we create, not discover, ethical truths. Mackie's support for this conception of ethics is roughly the following: (1) We cannot find objective values in isolation so they are not real. (2) We can find values in context so they must not be objectively real. I have problems with both of these premises. The first might be explained by Mackie's ill-suited isolatory method which I have already discussed. The second premise might be explained by developing a contextual realism.

One way of doing this is to bring together Mackie's notion of 'institution' with David O. Brink's notion of 'constitution.' Brink offers us a way of bypassing Mackie's reliance on an identity between natural facts and moral facts by offering the explanation that moral facts are not identical with, but constituted by, natural facts. Brink explains that, "moral facts and properties are constituted by, and so supervene upon, natural (i.e., natural and social scientific) facts and properties. Determinations of just which natural facts and properties constitute which moral facts and properties is a matter of substantive moral theory...." (Brink 1989: 177-178). This seems to be a very fruitful method. Making this distinction offers an understanding of the relationship between natural facts and moral facts.

But the constitution of moral facts by natural facts is still a concept that needs more analysis. It is, of course, of direct relevance to the supervenience problem. Although we cannot explicitly tell exactly which natural facts offer necessary and sufficient conditions for becoming moral facts, should we give up the project? I don't think we should. The moral/natural relation might be similar to the relations found between ecosystems for example. There is so much inter-level connection among ecosystems that the more we understand the less we know we know (Norton 1987: 205). But notice that the ecosystem example is a case of strictly empirical scientific observation, one that is totally concerned with natural facts and yet we cannot find the relations between ecosystems. When we humans try to help particular ecosystems we often end up causing more harm than good because we cannot predict with accuracy what consequences our tamperings will have on the various parts of the environment. This is also true in the case of species extinction. If scientists can predict what effects a species becoming extinct will have on a whole ecosystem, for example, then we would be able to determine which species we wouldn't mind allowing to become extinct. Bryan G. Norton explains:

To answer this kind of question one would have to know the detailed interrelationships and interdependencies among all the species. This requires, in turn, knowing which species are "keystone" species, knowing which species are redundant, and knowing how much the life cycles of various species can be disturbed before they can no longer support other species dependent upon them. Scientists are very far from having this sort of detailed understanding of any particular natural ecosystem. (Norton 1987: 50)

Our sciences cannot precisely predict the far-reaching, rippling effects that our tinkerings have on the environment because they do not adequately understand the relations between ecosystems. The same may be true of 
natural facts and moral facts. They are linked in deeply complex ways that simple linguistic analysis alone cannot elucidate.

Mackie's negative thesis, which predicts the failure of any attempt to find exactly which natural facts are connected to terms such as ought and 'good', might be perfectly true. However, if we place moral properties in a context or institution we find the connection starts to make sense. Mackie himself agrees to this when he reports that:

the popular formulation of [Hume's] law is misleading. From sets of 'is'-statements which are purely factual, which conceal no value terms, we can derive not only hypothetically imperative 'ought'-statements but also moral ones. Admittedly we do so only by speaking within some institution (p.72).

There is a connection, then, between natural facts and moral facts but it only obtains in an institution or more generally, in a context. At this time it would be helpful to draw a distinction between an 'institution' and a 'context'. They both basically refer to systems of relationships. With both of these notions I have in mind what Norton called 'interrelationships and interdependencies'. The difference between an 'institution' and a 'context' is that an institution is a narrower system of interrelationships because it has to do with essentially human-made practices, customs, traditions and the like. This understanding is supported by the etymological roots which means to establish, ordain or set up.

A context, on the other hand, is a much broader term which covers all forms of being, whether human, non-human, animate or inanimate. This interpretation is etymologically sound also for its roots indicate a coming together, a coherence or a weave. It is clearly a much more general term than institution.

Since the moral realist who advocates such notions as 'common moral principles' or 'intrinsically desirable values' wants to say these notions are common in an inter-institutional way, then simply to say these common moral principles obtain within an institution comes up short. What is intended by the moral realist is that these common principles obtain (or at least ought to obtain) in all institutions. Therefore moral realists need to utilize a broader term. This is why I am suggesting a contextual moral realism, one that obtains in all institutions not just in a contingent few.

Someone might point out that what I mean by contextual moral realism sounds very similar to objective moral realism. This is true. But why, then, call it contextual at all? The reason is to highlight and impress upon the antirealist the fact that this brand of moral realism is not open to the isolatory criticisms such as supervenience, for example, which attempts to stalemate moral realism by asking it to supply identity conditions for natural features and moral features. A straightforward objective moral realism that doesn't employ the notion of context will not withstand the isolatory line of criticism.

Let's say then that moral facts can only be located within a context. What follows from this? A first interpretation offered by someone of relativist bent such as Mackie would be quick to point out that ethics, since it depends on the contextual situation, must be an artificial creation. Since ethics can change depending on numerous contingencies surrounding the generation of the institution in question, we should not expect ethics to be anything other than a wholly invented creation. The relativist will ask why 
we should falsely presume that ethics has any kind of objective value at its core given that it is built on shifting sands.

$\AA$ second interpretation of this contextual thesis, offered by someone inclined towards moral realism would look for the deeper meaning and might point out that moral properties are complex properties involved in complex relationships. It is no wonder to such a contextual realist that a moral property cannot be reduced to one natural fact. Understanding an objective value is not like 'seeing red' or analyzing terms like 'ought' or 'good' in a definitional, linguistic, or isolatory, sense. It simply might be an attribute of the nature of moral properties that they can only be discovered in a social setting - somewhat like sociological facts. Although moral facts can only be found in contexts, and can only exist in contexts, this does not entail that they are not facts, or that they are less real than natural facts. It may be that we cannot isolate the nature of each particular moral fact and its exact relationship to natural facts, but that doesn't mean or entail that moral facts are insignificant.

I am not saying that when we have a general idea of how something, (viz. a moral fact), is created, (viz. by its context), then we have the full story. Certainly we should try to uncover the detailed relationships between moral facts and natural facts to the best of our ability. But there are different ways to approach this issue. Blackburn confesses that his challenge to the moral realist regarding the supervenience relation was originally aimed at Moore (I suspect the same is true of Mackie) and so it is not surprising that the supervenience argument might fail against other forms of moral realism.4 James Dreier points out that the supervenience argument is a hollow victory over moral realism because no one holds Moore's non-naturalism anymore and there are other plausible forms of moral realism such as reductive naturalism and non-reductive naturalism that take the mystery out of the supervenience relation. 5

So, although the whole of the moral fact is reducible to a particular sum of natural parts it does not follow, then, that if we understand a set of natural facts we would not be able to tell which moral facts correlate with which natural facts. Nicholas Sturgeon explains the position of nonreductive naturalism notably well:

An older argument required that, if we are to regard moral facts as natural, we must possess an analytic reduction of moral to nonmoral terminology. But it has been decades since anyone seriously proposed a comparable requirement on any other branch of inquiry-such as biology or psychology - that wished to prove its naturalistic credentials, and it thus seems quite arbitrary to apply it (as I think few would now do) to ethics. 6

A non-reductive naturalism of this sort explains Mackie's epistemological supervenience difficulty because it says there are not analytic relationships between moral facts and natural facts. And Mackie's metaphysical charge against moral realism is explained with the contextual thesis above.

In conclusion, if I can reduce a human to its elements found on a periodic table have I made any headway towards truly understanding the

4 "Supervenience Revisited", reprinted in (Blackburn 1993), p. 130.

5 Dreier 1992, pp. $18-19$.

6 Sturgeon 1991, p.32. 
human person? Analogously, if I reduce ethics to its basic elements will I truly understand the nature of ethics? No, both of these inquiries need a context $-a$ realist context if we are to be provided with a complete picture of the human person and a complete picture of ethics.

Although Mackie's goal was to argue against objective values, his conception of the content of ethics has revealed something fundamental about normative theory in general. Underlying his and probably anyone else's normative theory are objective values, values that universally apply to all. This presupposes realism, particularly the Sayre-McCord version of realism mentioned at the outset of the chapter, because statements about these objective values will have truth values that are literally true, i.e. interinstitutionally. When we find a professed anti-realist presupposing objective values in normative theory it serves as a small victory for the moral realist in the debate about the nature of ethics. 


\section{Works Cited}

Blackburn, Simon. 1971. "Moral Realism." In (Ed.) John Casey Morality and Moral Reasoning. London: Methuen \& Co. LTD.

. 1985. "Errors and the Phenomenology of Value." In Honderich 1985, pp. 1-22.

-1988. "Supervenience Revisited." In Sayre-McCord 1988a.

-1. 1993. Essays in Quasi-Realism. New York: Oxford University Press.

Brink, David O. 1989. Moral Realism and the Foundations of Ethics. Cambridge: Cambridge University Press.

James Dreier. 1992. "The Supervenience Argument Against Moral Realism." The Southern Journal of Philosophy XXX, No. 3, Pp. 13-38.

Gillespie, N. (ed.). 1986. Moral Realism: Proceedings of the 1985 Spindel Conference. The Southern Journal of Philosophy, Supplement 24.

Honderich, Ted (ed.) 1985. Morality and Objectivity: A Tribute to J.L. Mackie, London: Routledge \& Kegan Paul.

Horgan, Terence and Timmons, Mark. 1990-91. "New Wave Moral Realism Meets Moral Twin Earth." Joumal of Philosophical Research 16, Pp. 447465.

-2. 1992. "Troubles on Moral Twin Earth: Moral Queerness Revived," Synthese 92 No. 2, pp. 221-260.

Mackie, J.L. 1974. The Cement of the Universe: A Study of Causation. New York: Oxford University Press.

Mackie, J.L. 1977. Ethics: Inventing Right and Wrong. New York: Penguin Books.

Mill, John Stuart. 1861. Utilitarianism. Indianapolis, IN: Hackett Publishing Co.

Norton, Bryan. 1987. Why Preserve Natural Variety. Princeton: Princeton Univ Press.

Sayre-McCord, Geoffrey.1986. "The Many Moral Realisms." In Gillespie 1986, pp. 1-22. Reprinted in Sayre-McCord 1988a.

- 1988a. Essays on Moral Realism. Ithaca: Cornell University Press.

-1988b. "Moral Theory and Explanatory Impotence." In Sayre-McCord 1988a.

Sturgeon, Nicholas L. 1991. "Contents and Causes: A Reply to Blackburn." Philosophical Studies 61, Nos. 1-2, pp. 19-37.

Tannsjo, Torbjorn. 1976. The Relevance of Metaethics to Ethics. Stockholm: Almquist \& Wiksell International. 